\title{
Radiation exposure to staff members during traction X-rays
}

\author{
P Knott, ${ }^{*}$ M McGirk, A Markovic \\ From 9th International Conference on Conservative Management of Spinal Deformities - SOSORT 2012 \\ Annual Meeting \\ Milan, Italy. 10-12 May 2012
}

\section{Background}

Determining the flexibility of a scoliosis curve is important, during both conservative and surgical management, and traction $\mathrm{x}$-rays of the patient's spine are frequently done as part of this evaluation. The traction $\mathrm{x}$-ray is done with the patient in the supine position, and with staff members pulling on the patient's arms and legs. The use of staff to produce the traction radiograph has two major disadvantages: the pull on the arms and legs is not standardized, and the staff is exposed to $\mathrm{x}$-ray each time they perform a radiograph. Ingegno [1] determined that exposure to personnel applying arm traction, for cervical radiographs, was $0.01 \mathrm{mGy}$. But there are few studies that assess the radiation exposure to staff during imaging for AIS. It has been determined that a typical spinal radiograph exposes the patient to $3.2(+/-1.6)$ mGy of radiation. [2]

\section{Aim}

The aim of this study was to measure the amount of radiation a staff member is exposed to while participating in a traction $x$-ray of a patient with AIS.

\section{Methods}

The $\mathrm{x}$-ray table was set up and a phantom block of plastic was used to provide the same $\mathrm{x}$-ray scatter as a human body. An electronic $x$-ray survey detector was used at the head and foot of the table, in the same position that a staff member's head would be during traction. Radiographs were taken, and measurements of the amount of scatter were recorded.

\section{Results}

The scatter produced was 0.003 to $0.009 \mathrm{mGy}$ at the level of the staff member's head. Given that staff wears a lead apron, the torso dose would be negligible, so the exposure to the eyes and thyroid would be the most clinically important.

\section{Conclusion}

The recommended limit of exposure to the eyes for a staff member is $150 \mathrm{mGy}$ per year [2]. With the exposure that we measured, the staff member would not reach this limit until they performed 17,000 to 50,000 procedures. However, since this dose of $x$-ray to the staff member has no therapeutic benefits, it should still be reduced whenever possible.

\section{Published: 3 June 2013}

\section{References}

1. Ingegno M, Nahabedian M, Tominaga GT, Scannell G, Waxman K: Radiation exposure from cervical spine radiographs. Am J Emerg Med 1994, 12(1):15-16.

2. H-33 C: Task Force for the Inspection Protocol of Diagnostic X-Ray Facilities Using CR/DR Technology, Computed Radiography and Digital Radiography State X- Ray Inspection Protocol. CRCPD Publication; 2010\# E-10-2.

doi:10.1186/1748-7161-8-S1-P16

Cite this article as: Knott et al:: Radiation exposure to staff members

during traction X-rays. Scoliosis 2013 8(Suppl 1):P16. 